Article

\title{
Enhanced Solubility and Anticancer Potential of Mansonone G By $\beta$-Cyclodextrin-Based Host-Guest Complexation: A Computational and Experimental Study
}

\author{
Panupong Mahalapbutr ${ }^{1}$, Piyanuch Wonganan ${ }^{2}$, Thanapon Charoenwongpaiboon ${ }^{3}$ (D), \\ Manchumas Prousoontorn ${ }^{3}$, Warinthorn Chavasiri ${ }^{4}$ and Thanyada Rungrotmongkol 1,5,6,* \\ 1 Structural and Computational Biology Research Unit, Department of Biochemistry, Faculty of Science, \\ Chulalongkorn University, Bangkok 10330, Thailand; p.mahalapbutr@gmail.com \\ 2 Department of Pharmacology, Faculty of Medicine, Chulalongkorn University, Bangkok 10330, Thailand; \\ piyanuch.w@chula.ac.th \\ 3 Starch and Cyclodextrin Research Unit, Department of Biochemistry, Faculty of Science, Chulalongkorn \\ University, Bangkok 10330, Thailand; thanapon.charoenwongpaiboon@gmail.com (T.C.); \\ manchumas.h@chula.ac.th (M.P.) \\ 4 Center of Excellence in Natural Products Chemistry, Department of Chemistry, Faculty of Science, \\ Chulalongkorn University, Bangkok 10330, Thailand; warinthorn.c@chula.ac.th \\ 5 Ph.D. Program in Bioinformatics and Computational Biology, Faculty of Science, Chulalongkorn University, \\ Bangkok 10330, Thailand \\ 6 Molecular Sensory Science Center, Faculty of Science, Chulalongkorn University, Bangkok 10330, Thailand \\ * Correspondence: t.rungrotmongkol@gmail.com
}

Received: 20 September 2019; Accepted: 26 September 2019; Published: 27 September 2019

check for updates

\begin{abstract}
Mansonone G (MG), a plant-derived compound isolated from the heartwood of Mansonia gagei, possesses a potent antitumor effect on several kinds of malignancy. However, its poor solubility limits the use for practical applications. Beta-cyclodextrin ( $\beta C D)$, a cyclic oligosaccharide composed of seven $(1 \rightarrow 4)$-linked $\alpha$-D-glucopyranose units, is capable of encapsulating a variety of poorly soluble compounds into its hydrophobic interior. In this work, we aimed to enhance the water solubility and the anticancer activity of MG by complexation with $\beta C D$ and its derivatives (2,6-di-O-methyl- $\beta C D(D M \beta C D)$ and hydroxypropyl- $\beta C D)$. The 90-ns molecular dynamics simulations and MM/GBSA-based binding free energy results suggested that DM $\beta C D$ was the most preferential host molecule for MG inclusion complexation. The inclusion complex formation between $M G$ and $\beta C D(s)$ was confirmed by DSC and SEM techniques. Notably, the MG/ $\beta C D s$ inclusion complexes exerted significantly higher cytotoxic effect ( $\sim 2-7$ fold) on A549 lung cancer cells than the uncomplexed MG.
\end{abstract}

Keywords: beta-cyclodextrins; inclusion complex; mansonone G; molecular dynamics simulation; lung cancer

\section{Introduction}

Cancer is a major public health issue and is ranked as the second leading cause of mortality worldwide following cardiovascular disease [1]. Several plant-derived compounds containing naphthoquinone (NQ) moiety such as beta-lapachone, plumbagin, and shikonin have been reported to exert a superior antiproliferative activity [2-4]. Mansonones, group of ortho-NQ-containing compounds, are the major bioactive constituents of the diverse plant genera, including Mansonia, Hibiscus, and Thespesia [5]. Previous studies revealed that mansonones D, E, F, and H possess the anticancer effect on 
several kinds of solid tumors [6-8]. In addition, the novel derivative of mansonone F exhibited 20-fold stronger DNA topoisomerase II inhibitory activity than the chemotherapeutic drug etoposide [9].

Among the eight different mansonones (mansonones A-H) [10], mansonone G (MG, Figure 1A) is the major product isolated from the heartwood of Mansonia gagei Drumm., Sterculiaceae family found in Thailand [11]. Many lines of evidence have shown that MG exhibits a potent anticarcinogenic effect on various types of malignancies, e.g., ovarian (A278, IC 50 of $10.2 \mu \mathrm{M}$ ), colorectal (HCT116, IC I0 $_{50} 63.4$ $\mu \mathrm{M}$ ), liver (HepG2, IC $\mathrm{IC}_{50}$ of $36.3 \mu \mathrm{M}$ and Huh-7, $\mathrm{IC}_{50}$ of $25.9 \mu \mathrm{M}$ ), breast (MCF-7, IC 50 of $23.0 \mu \mathrm{M}$ ), and cervical (HeLa, $\mathrm{IC}_{50}$ of $\left.18.8 \mu \mathrm{M}\right)$ cancer cell lines [5,12,13], and it has been documented to significantly inhibit the activity of P-glycoprotein efflux pump [5]. Recently, the butoxy MG has shown to potentially induce cell apoptosis in human lung cancer cell lines A549 and H1975 by inhibiting STAT3 and Akt signaling pathways [14]. Even though MG could serve as a promising anticancer agent, its poor water solubility $\left(1.7 \mathrm{mg} / \mathrm{L}\right.$ at $\left.30^{\circ} \mathrm{C}\right)$ leads to a limited use for pharmaceutical and medicinal applications.

Cyclodextrin (CD), a naturally occurring cyclic oligosaccharide produced by CD glucanotransferase (CGTase)-catalyzed starch degradation [15], has a unique structure representing a hydrophobic inner cavity and a hydrophilic outer surface. Consequently, CD can potentially enhance the solubility, stability, and pharmacological properties of many lipophilic guest molecules $[16,17]$ through the formation of an inclusion complex driven mainly by van der Waals (vdW) interactions [18]. The common types of CD are alpha $(\alpha)$, beta $(\beta)$, and gamma $(\gamma)$ CDs formed by six, seven, and eight $\alpha$-D-glucopyranose units, respectively. Among the three CDs, $\beta C D$ (Figure 1B) is the most commonly used in many pharmaceutical purposes due to its low price, easy synthetic access, and structural orientation suitable for inclusion complex generation $[19,20]$. However, the low water solubility $\left(18.5 \mathrm{mg} / \mathrm{mL}\right.$ at $\left.25^{\circ} \mathrm{C}\right)$ and nephrotoxicity of $\beta C D$ limit its use for practical applications [21].

In recent years, the use of $\beta C D$ derivatives (e.g., methylated $(\mathrm{M})$ and 2-hydroxypropylated (HP) $\beta C D s$ ) for host-guest encapsulation has gained much attention in an attempt to improve the water solubility and to reduce the limitations of natural $\beta C D$. The $\mathrm{M} \beta C D$ (e.g., 2,6-di-O-methyl- $\beta C D$; $\mathrm{DM} \beta C D$ ) and the HP $\beta C D$ derivatives exhibit higher aqueous solubility and lower toxicity than the unmodified $\beta C D$ [21-23]. Several experimental and theoretical reports (both classical molecular dynamics (MD) and density functional theory (DFT)) have demonstrated that the water solubility, chemical stability, and anticancer activity of poorly soluble molecules are significantly improved by complexation with $\mathrm{DM} \beta C D$ and $\mathrm{HP} \beta C D$ derivatives [24-28]. However, the information on the inclusion complexes of MG with $\beta C D$ s has never been previously reported. Therefore, the present study aimed to enhance the physical and biological properties of $M G$ using $\beta C D$ and its derivatives $(D M \beta C D$ and $H P \beta C D)$ based on working hypothesis that the anticancer activity of MG may be positively affected by $\beta C D$ s. The all-atom MD simulations and binding free energy calculations were firstly applied ( $i$ ) to search for the suitable $\beta C D$ encapsulating molecule for MG and (ii) to investigate the atomistic insights into host-guest complexation and its underlying interactions. Subsequently, the phase solubility study between MG and $\beta C D$ s was experimentally verified, and the physical and chemical characterization techniques were used to confirm the inclusion complex formation. Finally, the resulting $\mathrm{MG} / \beta \mathrm{CDs}$ complexes were subjected to evaluate the antitumor activity toward A549 human lung cancer cell line in comparison to the MG alone.

\section{Materials and Methods}

\subsection{Computational Details}

The 3D structures of MG and all the investigated $\beta C D$ analogs $(\beta C D, D M \beta C D, 2 H P \beta C D, 6 H P \beta C D$, and $D H P \beta C D$ ) were taken from previous studies [29-31]. It should be noted that (i) the hydroxyl group of MG is protonated (neutral form) based on NMR data from previous studies [11,32] and (ii) the commercially available $\mathrm{HP} \beta C D$ is a mixture of various degree of substitution (DS), while the models we built in this study were fully $(\mathrm{DHP} \beta C \mathrm{C}$; DS $=14$ ) and partially $(2 \mathrm{HP} \beta C \mathrm{C}$ and $6 \mathrm{HP} \beta C \mathrm{CD} ; \mathrm{DS}=7$ ) substituted HP $\beta C D$ s. The inclusion complexes were generated in Accelrys Discovery 
Studio 2.5 (Accelrys Software Inc., San Diego, CA, USA) by docking protocols using CDOCKER module. The partial charges of MG molecule were created as per the standard procedures [33-35]. The Glycam-06 [36] and general AMBER force fields [37] were applied on $\beta C D$ s and MG, respectively. Using a truncated octahedral box, the TIP3P water molecules were used to solvate around MG/ $\beta C D$ s complexes with a spacing distance of $15 \AA$. After that, the added water molecules were minimized using 1000 steps of steepest descent and continued by 3000 steps of conjugated gradient. Lastly, the whole model was optimized as per the same methods.

Under periodic boundary condition with a time step of $2 \mathrm{fs}$, each solvated inclusion complex was heated up from $10 \mathrm{~K}$ to $303 \mathrm{~K}$ for $60 \mathrm{ps}$, and followed by all-atom MD simulations (NPT ensemble, temperature of $303 \mathrm{~K}$ and pressure of $1 \mathrm{~atm}$ ) using AMBER16 for $90 \mathrm{~ns}$ in triplicate. All chemical bonds involving hydrogen were constrained using the SHAKE algorithm [38]. The particle mesh Ewald method [39] was employed to treat charge-charge interactions with a cutoff of $12 \AA$. The molecular mechanics/generalized Born surface area (MM/GBSA)-based binding free energy ( $\left.\Delta G_{\text {bind, MM/GBSA }}\right)$ calculation [40] was used to estimate the binding affinity of all the studied inclusion complexes.

\subsection{Experimental Part}

\subsubsection{Chemical Reagents}

MG was extracted from Mansonia gagei Drumm according to the previous study [11]. $\beta C D$ (MW 1134.98) was obtained from Acros Organics (Morris Plains, NJ, USA), whereas the Heptakis(2,6-di-O-methyl)- $\beta$-cyclodextrin (DM $\beta C D$; MW 1331.36), (2-Hydroxypropyl)- $\beta$-cyclodextrin (HP $\beta C D$; MW 1396; average DS is 0.5-1.3 unit of 2-hydroxypropyl group per glucose unit), dimethyl sulfoxide (DMSO), and 3-(4,5-dimethylthiazol-2-yl)-2,5-diphenyltetrazolium bromide (MTT) were purchased from Sigma-Aldrich (St. Louis, MO, USA).

\subsubsection{Cell lines and Culture}

A549 human lung cancer cell line was obtained from Dr. Apiwat Mutirangura (Chulalongkorn University, Thailand). A549 cells were cultured in Dulbecco's modified Eagle's medium (DMEM; Gibco, Grand Island, NY, USA) containing 10\% fetal bovine serum (FBS; Gibco), $100 \mathrm{U} / \mathrm{mL}$ penicillin, and $100 \mu \mathrm{g} / \mathrm{mL}$ streptomycin (Gibco) and were maintained at $37^{\circ} \mathrm{C}$ in a humidified $5 \% \mathrm{CO}_{2}$ atmosphere.

\subsubsection{Phase Solubility Study and Evaluation of Thermodynamic Parameters}

Phase solubility study was conducted by following the method of Higushi and Connors [41]. Briefly, an excess amount of MG was added to $\beta C D(\mathrm{~s})$ solutions $(0-10 \mathrm{mM})$. The mixtures were shaken (250 rpm) at $30^{\circ} \mathrm{C}, 37^{\circ} \mathrm{C}$, and $45^{\circ} \mathrm{C}$ for $72 \mathrm{~h}$. Subsequently, the suspensions were centrifuged at $12,000 \mathrm{rpm}$ for $15 \mathrm{~min}$. The amount of MG presenting in solution was measured by UV-Vis spectroscopy at $415 \mathrm{~nm}$. The Equation (1) was used to calculate the apparent stability constant $\left(K_{c}\right)$, where $S_{0}$ is y-intercept.

$$
K_{c}=\frac{\text { Slope }}{\left[S_{o}(1-\text { slope })\right]}
$$

The Van't Hoff plot based on Equation (2) [17] was used to identify the thermodynamic properties, including enthalpy $(\Delta H)$ and entropy $(\Delta S)$ changes of inclusion complexation, whilst the experimental Gibbs free energy $\left(\Delta G_{\text {bind, exp }}\right)$ was obtained from Equation (3).

$$
\begin{gathered}
\ln K_{c}=-\frac{\Delta H}{R T}+\frac{\Delta S}{R} \\
\Delta G_{\text {bind, } \exp }=\Delta H-T \Delta S
\end{gathered}
$$




\subsubsection{Inclusion Complex Preparation}

A 1:1 stoichiometric ratio of $\mathrm{MG} / \beta \mathrm{CD}(\mathrm{s})$ inclusion complex was prepared by the freeze-drying method. Each accurately weighed compound (73.28 mg MG, $340.49 \mathrm{mg} \beta C D, 399.41 \mathrm{mg} D M \beta C D$, and $418.80 \mathrm{mg} H P \beta C D)$ was dissolved in deionized water $(30 \mathrm{~mL})$, then the mixture was magnetically stirred at room temperature for $24 \mathrm{~h}$. After that, the suspension was centrifuged (12,000 rpm for $15 \mathrm{~min})$ and filtered through a $0.45 \mu \mathrm{m}$ filter. The obtained solution was then frozen overnight at $-80{ }^{\circ} \mathrm{C}$ and subsequently lyophilized using LYO-LAB (Lyophilization Systems Inc., USA) for 3 days. In addition, a 1:1 molar ratio of $\mathrm{MG}$ and $\beta C D(\mathrm{~s})$ was physically mixed at room temperature to obtain the physical mixtures, which were used for comparison. The resulting freeze-dried powders and physical mixtures were stored in desiccator for further use.

\subsubsection{Determination of Solubility}

Excess quantity of pure MG and its inclusion complexes was added to $1 \mathrm{~mL}$ of deionized water. The mixture was continuously stirred at $30^{\circ} \mathrm{C}$ for $24 \mathrm{~h}$. Subsequently, the suspension was filtered through a $0.45 \mu \mathrm{m}$ filter, and the solubility of MG was characterized by measuring the absorbance at a wavelength of $415 \mathrm{~nm}$.

\subsubsection{Inclusion Complex Characterization}

Differential Scanning Calorimetry (DSC)

The thermal behavior of the MG, $\beta C D, D M \beta C D, M G / \beta C D$, and $M G / D M \beta C D$ was characterized using NETZSCH DSC 204F1 Phoenix. Each solid sample ( 1-2 mg) was heated from $25^{\circ} \mathrm{C}$ to $300^{\circ} \mathrm{C}$ in aluminum pans at a rate of $10{ }^{\circ} \mathrm{C} / \mathrm{min}$.

\section{Scanning Electron Microscope (SEM)}

The surface morphology of $M G, \beta C D, D M \beta C D$, the freeze-dried inclusion complexes, and the physical mixtures was analyzed using a Scanning Electron Microscope (JEOL JSM-IT500HR). Samples were coated with a thin layer of gold in vacuum before viewing under 300 times magnification. Observations were performed using an accelerating voltage of $10 \mathrm{kV}$.

\subsubsection{Cytotoxicity of MG toward Lung Cancer Cells}

Cell viability was evaluated using MTT assay. A549 cells were seeded into 96-well plates at a density of $3 \times 10^{3}$ cells/well. After overnight incubation, cells were treated with logarithmic concentrations $(1,3,10,30$, and $100 \mu \mathrm{M})$ of MG, MG/ $\beta C D, M G / D M \beta C D$, and MG/HP $\beta C D$ for $48 \mathrm{~h}$. Note that the amount of treated MG in free form and in complexes is equivalent. After that, MTT solution $(5 \mathrm{mg} / \mathrm{mL})$ was added to each well and then incubated at $37^{\circ} \mathrm{C}$ for another $4 \mathrm{~h}$. Subsequently, the culture medium was withdrawn and $150 \mu \mathrm{L}$ of DMSO solution was added to dissolve formazan crystals. Finally, the absorbance was measured at $570 \mathrm{~nm}$ using UV-Vis spectrophotometer (Thermo Scientific, Vantaa, Finland). The half-maximal inhibitory concentration $\left(\mathrm{IC}_{50}\right)$ was calculated using GraphPad Prism 7 software.

\subsubsection{Statistical Analysis}

The quantitative data are expressed as mean \pm standard error of mean (SEM) of three independent experiments. Differences between groups were determined using one-way analysis of variance (ANOVA) followed by a Newman-Keuls post hoc test. The $p$ value of $\leq 0.05$ was considered statistically significant. 
(A)
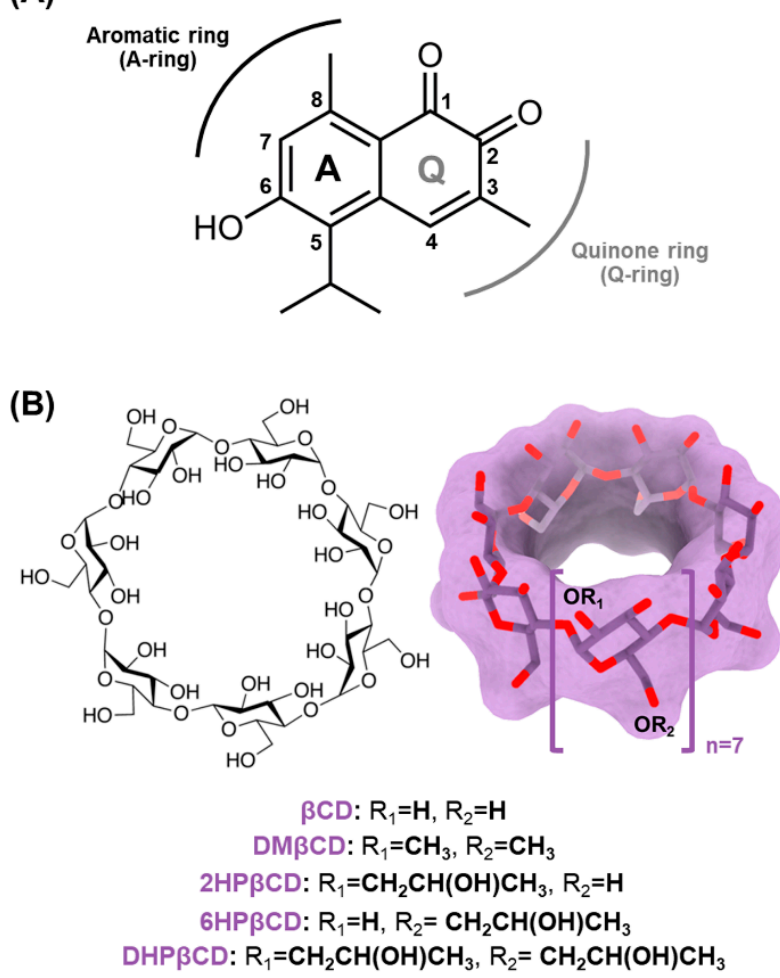

Figure 1. (A) $2 \mathrm{D}$ structure of MG. (B) $2 \mathrm{D}$ and $3 \mathrm{D}$ structures of $\beta C D$, where the functional substitutions used in this study are shown below.

\section{Results and Discussion}

From docking study, MG could form two possible inclusion complexes with $\beta C D$ s through its aromatic ring (A-ring, form I) or quinone ring (Q-ring, form II) insertion into the hydrophobic cavity. However, after performing all-atom MD simulations for $90 \mathrm{~ns}$ in triplicate on both forms (altogether 30 independent simulations), only form I of $M G / \beta C D, M G / D M \beta C D$, and $M G / 2 H P \beta C D$ is likely stable, whilst the dissociation of inclusion complex is detected in the form II of all systems as well as the form I of MG/6HP $\beta C D$ and MG/DHP $\beta C D$. The latter finding is consistent well with previous study showing that the HP modification on $\beta C D$ at $C 6$-position $(D S=7)$ led to the dissociation of the encapsulated mansonones $\mathrm{E}$ and $\mathrm{H}$ from hydrophobic inner cavity [42]. Therefore, the $\mathrm{MG} / \beta C D, \mathrm{MG} / \mathrm{DM} \beta C D$ (DS = 14), and MG/2HP $\beta C D$ (DS = 7) complexes in form I were further focused in this study.

\subsection{Ligand Mobility Inside $\beta C D$ 's Hydrophobic Cavity}

The dynamics behavior of the encapsulated MG inside hydrophobic interior of $\beta C D(s)$ along the simulation time was studied using the calculations of the distance between the center of mass $\left(C_{m}\right)$ of each ring of MG (A-ring (black) and Q-ring (grey)) and the $C_{m}$ of $\beta C D$ without taking into account the functional substituents. The obtained results are shown in Figure 2A, whereas the representative binding mode of $M G / \beta C D(s)$ taken from the final MD snapshot is depicted in Figure 2B. The horizontal grey box ranging from $-3.95 \AA$ to $3.95 \AA(\sim 7.9 \AA)$ represents the positions of the primary (narrow) and secondary (wider) rims of native $\beta C D$, respectively [43]. In the case of $M G / \beta C D$ and $M G / 2 H P \beta C D$ systems, MG stably positions nearby the wider rim of $\beta C D(s)$ and preferentially inserts the A-ring inside the hydrophobic inner cavity. By considering the MG/DM $\beta C D$ models, MG rapidly moves toward the narrow rim of $\mathrm{DM} \beta \mathrm{CD}$ after the heating step and subsequently positions in this orientation until the end of the simulations. 


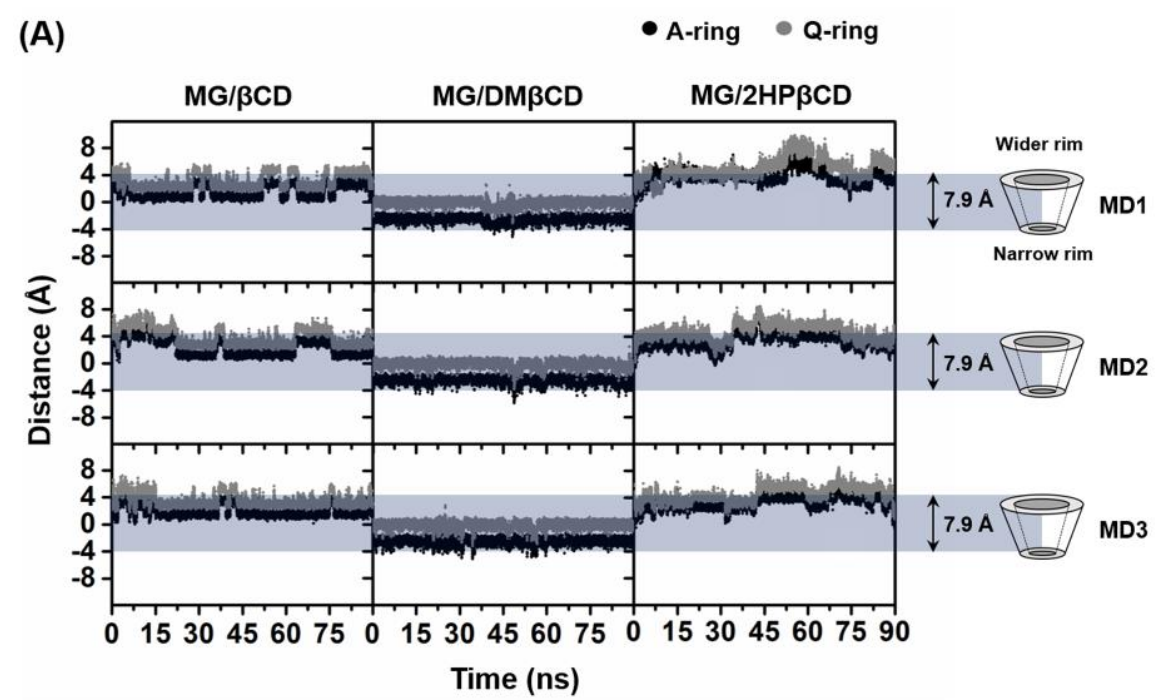

(B)
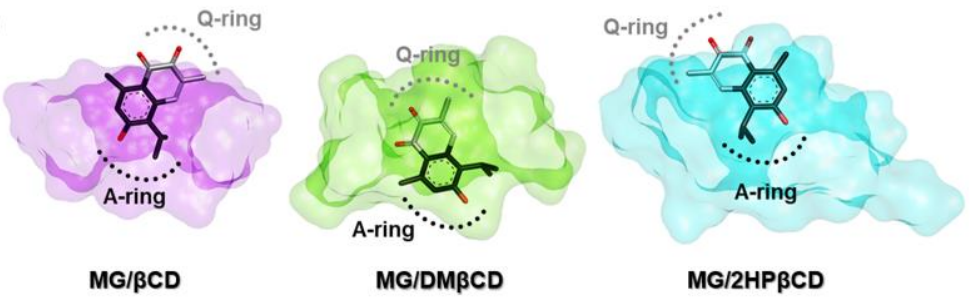

MG/2HPßCD

Figure 2. (A) The distance between $C_{m}$ of $M G$ ring $(A / Q)$ and $C_{m}$ of $\beta C D$ of all studied inclusion complexes for three independent MD simulations (MD1-3). (B) The binding orientation of MG inside $\beta C D$ (violet), $D M \beta C D$ (green), and $2 \mathrm{HP} \beta C D$ (cyan) cavities drawn from the last MD snapshot.

\section{2. $\beta C D$ s Conformations Upon MG Binding}

The $\beta C D(s)$ conformational changes upon MG encapsulation were investigated by calculating (i) the distance of the secondary hydroxyl groups on the wider rim of $\beta C D s\left(\mathrm{O}_{(\mathrm{n})}-\mathrm{O} 2_{(\mathrm{n}+1)}, \mathrm{dO}_{3-2}\right)$, corresponding to a possibility of intramolecular hydrogen bond (H-bond) generation ( $\mathrm{dO}_{3-2}$ of $\leq 3.5 \AA$ ), and (ii) the distance of glycosidic oxygen atoms $\left(\mathrm{O}_{(\mathrm{n})}-\mathrm{O}_{(\mathrm{n}+1)}, \mathrm{dO}_{4-4}\right)$ (Figure $3 \mathrm{~A}$, left). Afterward, the Equation (4) was used to transform the distributions of these two parameters into the free energy value, $\mathrm{F}(x, y)$ :

$$
\mathrm{F}(x, y)=-k_{\mathrm{B}} T \log [P(x, y)]
$$

where $k_{\mathrm{B}}$ is the Boltzmann constant, $T$ is the temperature (303 $\mathrm{K}$ ), and $P(x, y)$ is the probability of $\mathrm{dO}_{3-2}(\mathrm{x})$ and $\mathrm{dO}_{4-4}(\mathrm{y})$. The potential energy surface (PES) is shown in Figure $3 \mathrm{~A}$, in which the $\mathrm{M} 1$ area is the most stable form of the $\beta C D(s)$, whilst the M2 region represents the rotation of the $\alpha$-D-glucopyranose units.

As compared to the unbound form of $\beta C D$ s exhibiting three local minima areas: $\mathrm{M} 1$ ( $\mathrm{dO}_{3-2}$ of $\sim 3.0-4.5 \AA$ and $\mathrm{dO}_{4-4}$ of $\left.\sim 4.3-4.7 \AA\right), \mathrm{M} 2\left(\mathrm{dO}_{3-2}\right.$ of $\sim 5 \AA$ and $\mathrm{dO}_{4-4}$ of $\left.\sim 4.5-5.2 \AA\right)$, and $\mathrm{M} 3\left(\mathrm{dO}_{3-2}\right.$ of $\sim 5 \AA$ and $\mathrm{dO}_{4-4}$ of $\sim 6 \AA$ ) [30], the molecular encapsulation of MG toward $\mathrm{DM} \beta \mathrm{CD}$ and $2 \mathrm{HP} \beta C D$ dramatically induces the stable conformation of $\beta C D(s)$ by enhancing the formation of intramolecular H-bonds on the wider rim, as evidenced by the obviously increased population in $\mathrm{M} 1$ region $\left(\mathrm{dO}_{3-2}\right.$ of $\sim 2.5-4.5 \AA$ and $\mathrm{dO}_{4-4}$ of $\sim 4.1-4.9 \AA$, Figure $3 \mathrm{~A}$ ). In addition, the $\mathrm{M} 3$ region with both lengthened distances, which was only detected in the free form of $\beta C D$ s, is completely disappeared in all MG-bound systems. These H-bond-operated conformational changes of $\beta C D(s)$ upon the ligand binding correlate well with previously published research [44]. However, the distortion of glucopyranose units represented by $\mathrm{M} 2$ area is found in $\mathrm{MG} / \beta \mathrm{CD}$ and $\mathrm{MG} / 2 \mathrm{HP} \beta \mathrm{CD}$ systems, but not in $\mathrm{MG} / \mathrm{DM} \beta \mathrm{CD}$ models, indicating that MG/DM $\beta C D$ is the most stable complex, which is consistent with $\triangle G_{\text {bind, MM/GBSA calculations }}$

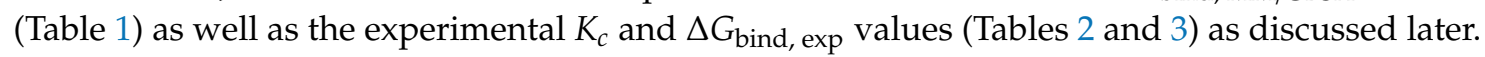


We further characterized the native contact points within $3 \AA$ between MG and $\beta C D$ s during the last 20-ns MD simulations. The obtained results (Figure 3B) reveal that MG/DM $\beta C D$ inclusion complex displays the highest number of contacts per $\alpha$-D-glucopyranose units $(6.97 \pm 0.62)$ followed by MG/2HP $\beta C D(6.58 \pm 0.78)$ and $\mathrm{MG} / \beta C D(6.06 \pm 0.40)$ complexes, respectively, as clearly shown by the representative $3 \mathrm{D}$ contact structures (Figure $3 \mathrm{~B}$, top) demonstrating that MG/DM $\beta C D$ exhibits the most compact feature. Altogether, the native-contact-driven structures consistently support the PES calculations.

(A)

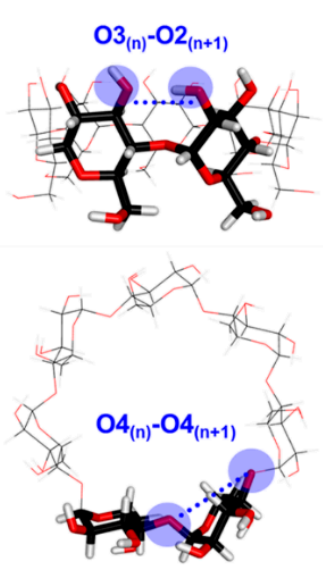

(B)
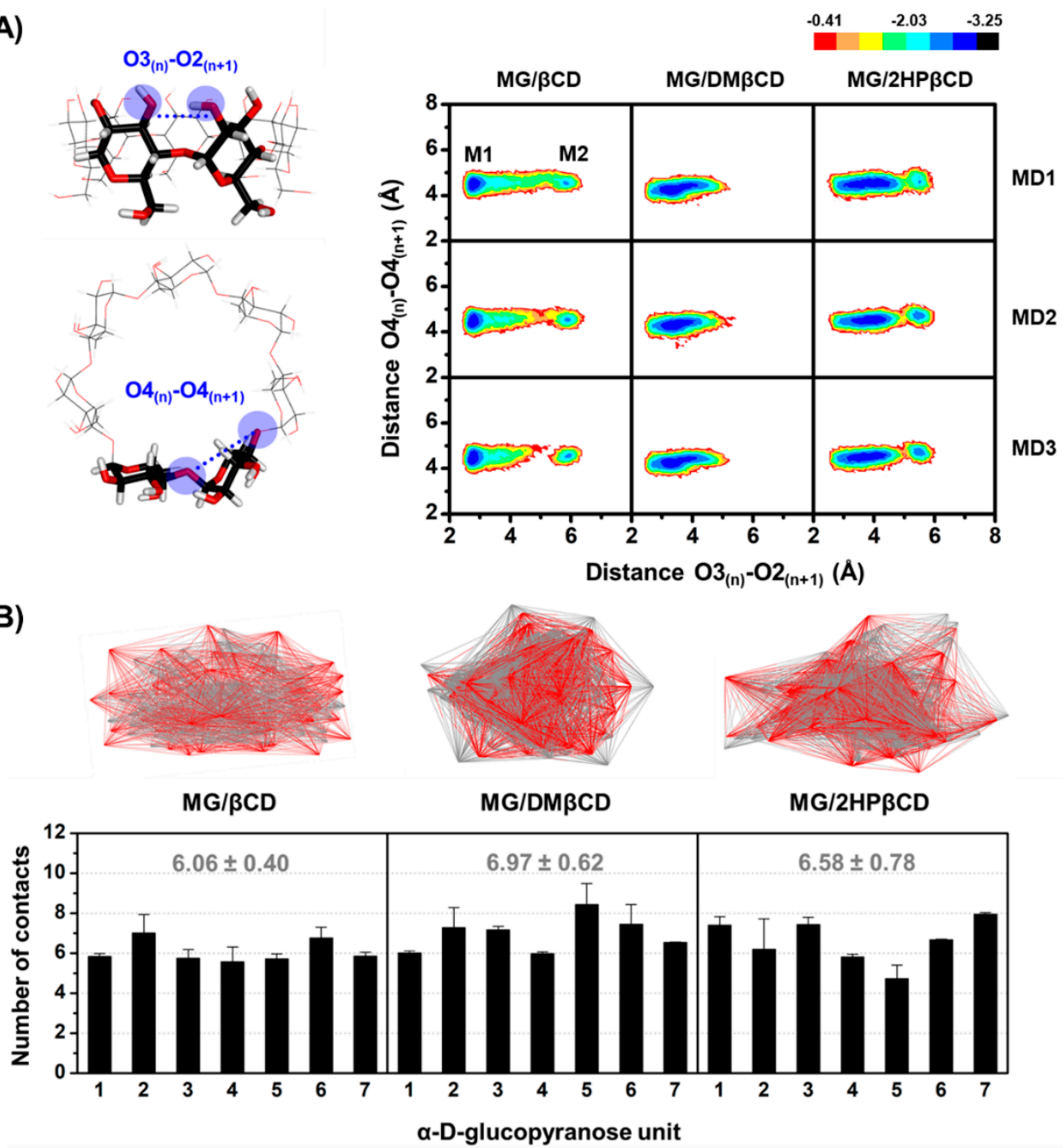

MG/2HPßCD (1)

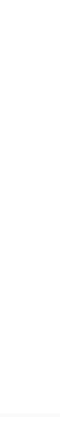

Figure 3. (A) The distance parameters $\left(\mathrm{dO}_{3-2}\right.$ and $\left.\mathrm{dO}_{4-4}\right)$ used for PES calculations (left) and the obtained results (right). (B) The representative native contact PDB structures shown in line mode (top) and the number of contacts between MG and $\alpha$-D-glucopyranose units of $\beta C D$ s (bottom). Data are expressed as mean $\pm \mathrm{SEM}$ of three independent MD simulations.

\subsection{Solvent Accessibility Toward Inclusion Complexes}

The effect of water accessibility on $\mathrm{MG} / \beta \mathrm{CD}(\mathrm{s})$ inclusion complex formation was characterized by solvent accessible surface area (SASA) calculations using MG as the atomic radii for solvent-exposed area. The entire SASA results are depicted in Figure 4A, whereas the average SASA values taken from the last 20-ns MD simulations are illustrated in Figure 4B.

Data in Figure $4 \mathrm{~A}$ indicate that the SASAs of MG/ $\beta C D$ and MG/DM $\beta C D$ systems are more stable than those of MG/2HP $\beta C D$ complexes. In the case of MG/ $\beta C D$, the SASAs fluctuate in the range of $\sim 150-250 \AA^{2}$, whereas the SASAs of MG/DM $\beta C D$ are relatively steady at $\sim 150 \AA^{2}$ along the simulation times. By considering the $\mathrm{MG} / 2 \mathrm{HP} \beta \mathrm{CD}$ models, the SASA values considerably 
fluctuate ( 200-300 $\AA^{2}$ ) at 40-70 ns and subsequently decrease to $\sim 150 \AA^{2}$ after 70 ns (except MD1). The average SASA values over the last $20 \mathrm{~ns}$ from three independent simulations in Figure $4 \mathrm{~B}$ reveal that the complexation of MG with $D M \beta C D$ significantly decreases the water accessibility toward the MG molecule inside hydrophobic inner cavity as compared to the MG/ $\beta C D$ and MG/2HP $\beta C D$ $\left({ }^{*} p \leq 0.05\right)$. These observations correlate well with previous study [45] demonstrating that the lowest solvent exposed inclusion complex displayed the highest binding affinity. However, the SASAs of $\mathrm{MG} / \beta C D$ and $\mathrm{MG} / 2 \mathrm{HP} \beta C D$ are not significantly different, suggesting that $\mathrm{DM} \beta C D$ is the most preferred encapsulating agent for MG, which is in good correlation with MM/GBSA-based free energy calculations as discussed in the next section.

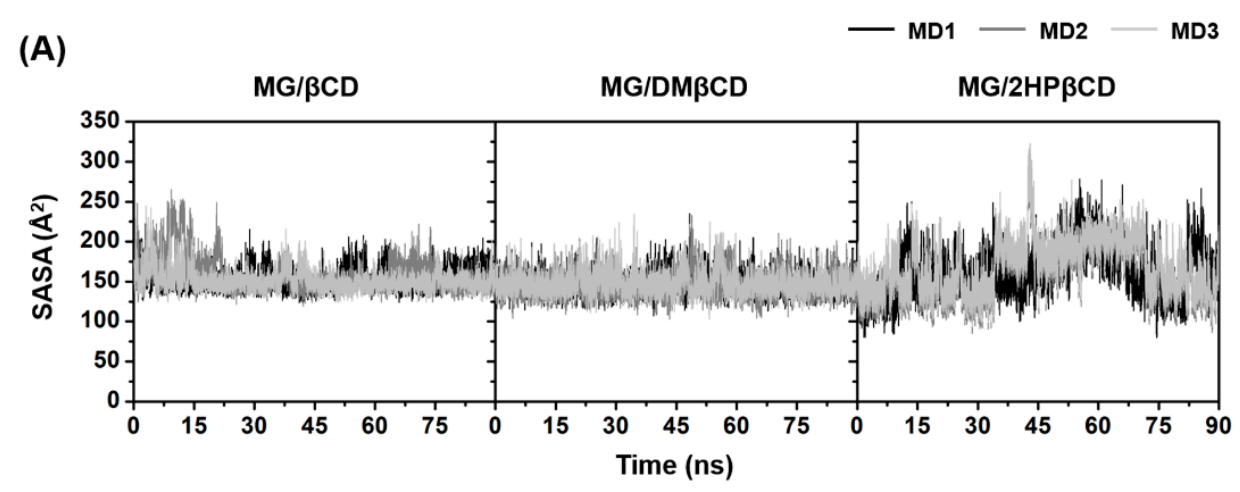

(B)

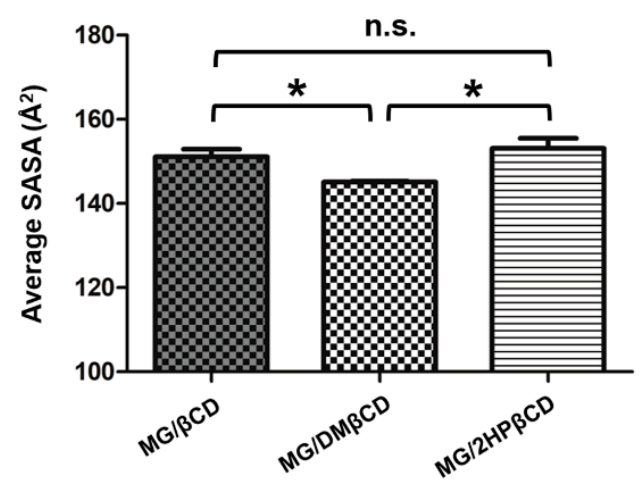

Figure 4. (A) SASA of $M G / \beta C D, M G / D M \beta C D$, and $M G / 2 H P \beta C D$ for three different $M D$ runs. (B) The average SASA over the last 20-ns MD simulations for each inclusion complex. Data are expressed as mean $\pm \operatorname{SEM}(n=3)$. n.s., not significantly different. ${ }^{*} p \leq 0.05$.

\subsection{Binding Free Energy of Inclusion Complexes}

To estimate the binding affinity of the inclusion complexes, we applied MM/GBSA [46] calculation on each $\mathrm{MG} / \beta C D(\mathrm{~s})$ using 300 snapshots extracted from the last 20-ns MD simulations. The average $\Delta G_{\text {bind, MM/GBSA }}$ and its energy components, $\operatorname{vdW}\left(\Delta E_{\mathrm{vdW}}\right)$ and electrostatic $\left(\Delta E_{\text {ele }}\right)$ energies, for $\mathrm{MG} / \beta C D$ s are summarized and compared in Table 1 . As expected, due to the poor solubility of MG, the host-guest complexation in gas phase is driven predominantly by $\mathrm{vdW}$ interactions $(\sim-27$ to $-29 \mathrm{kcal} / \mathrm{mol})$. Similarly, the summation of $\Delta G_{\text {solv,non-polar }}+\Delta E_{\mathrm{vdW}}$ energies $(\sim-30$ to $-32 \mathrm{kcal} / \mathrm{mol})$ is much lower than the $\Delta G_{\text {solv,polar }}+\Delta E_{\text {ele }}$ terms ( $\sim 8$ to $10 \mathrm{kcal} / \mathrm{mol}$ ), indicating the vdW forces play a pivotal role in the formation of $\mathrm{MG} / \beta C D$ s in an aqueous environment. These findings strongly correlate with those reported for other hydrophobic ligands in complex with $\beta C D s$ [47-49].

Several studies have shown that the methyl and hydroxypropyl modifications on $\beta C D$ can significantly enhance the stability of many lipophilic guest molecules [50-52]. In good agreement with these reports, our results demonstrate that the $\Delta G_{\text {bind, MM/GBSA }}$ of MG in complex with modified $\beta C D s$ is significantly lower than that of $M G$ in complex with unsubstituted $\beta C D$, which can be ranked in the order of MG $/ \beta C D(-2.34 \pm 0.35 \mathrm{kcal} / \mathrm{mol})>\mathrm{MG} / 2 \mathrm{HP} \beta C D\left(-3.35 \pm 0.14 \mathrm{kcal} / \mathrm{mol},{ }^{*}\right)>\mathrm{MG} / \mathrm{DM} \beta C D$ 
$\left(-5.73 \pm 0.04 \mathrm{kcal} / \mathrm{mol},{ }^{* * *}\right)$. Taken altogether, all structural and energetic analyses convince that $\mathrm{DM} \beta \mathrm{CD}$ analog is the most suitable host for MG encapsulation.

Table 1. The average $\Delta G_{\text {bind, MM/GBSA }}$ and its energy components $(\mathrm{kcal} / \mathrm{mol})$ of $\mathrm{MG} / \beta C D$ s inclusion complexes. Data are expressed as mean \pm SEM from three independent MD simulations. $\Delta E_{\mathrm{MM}}$, molecular mechanics energy; $\Delta G_{\text {solv }}$, solvation free energy comprising polar $\left(\Delta G_{\text {solv,polar }}\right)$ and non-polar $\left(\Delta G_{\text {solv,non-polar }}\right)$ terms; $\Delta S$, entropy. ${ }^{*} p \leq 0.05$ and ${ }^{* * *} p \leq 0.001$ vs. $\mathrm{MG} / \beta C D$.

\begin{tabular}{cccc}
\hline Energy Component (kcal/mol) & MG/ $\beta$ CD & MG/DM $\beta C D$ & MG/2HP $\beta C D$ \\
\hline$\Delta E_{\mathrm{vdW}}$ & $-27.61 \pm 1.19$ & $-29.19 \pm 0.29$ & $-28.59 \pm 0.64$ \\
$\Delta E_{\text {ele }}$ & $-11.79 \pm 0.40$ & $-4.43 \pm 0.19$ & $-6.40 \pm 0.90$ \\
$\Delta E_{\mathrm{MM}}$ & $-39.40 \pm 1.58$ & $-33.62 \pm 0.26$ & $-34.99 \pm 0.26$ \\
$\Delta G_{\text {solv,polar }}$ & $22.14 \pm 0.91$ & $12.72 \pm 0.13$ & $17.17 \pm 0.54$ \\
$\Delta G_{\text {solv,non-polar }}$ & $-2.83 \pm 0.04$ & $-2.98 \pm 0.01$ & $-3.10 \pm 0.02$ \\
$\Delta G_{\text {solv }}$ & $19.31 \pm 0.86$ & $9.73 \pm 0.12$ & $14.06 \pm 0.57$ \\
$\Delta G_{\text {solv,polar }}+\Delta E_{\text {ele }}$ & $10.35 \pm 0.53$ & $8.29 \pm 0.19$ & $10.77 \pm 0.47$ \\
$\Delta G_{\text {solv,non-polar }}+\Delta E_{\mathrm{vdW}}$ & $-30.44 \pm 1.24$ & $-32.18 \pm 0.31$ & $-31.69 \pm 0.66$ \\
T $\Delta S$ & $-17.74 \pm 0.36$ & $-18.16 \pm 0.13$ & $-17.57 \pm 0.42$ \\
$\Delta G_{\text {bind, MM/GBSA }}$ & $-2.34 \pm 0.35$ & $-5.73 \pm 0.04\left(^{* * *}\right)$ & $-3.35 \pm 0.14\left(^{*}\right)$ \\
\hline
\end{tabular}

\subsection{Phase Solubility Study and Thermodynamic Parameters}

As the molecular modeling results suggest that $\mathrm{DM} \beta \mathrm{CD}$ derivative is the most preferential host for MG, we further confirmed our findings by conducting the experimental phase solubility study and Van't Hoff-based thermodynamic parameter evaluation.

Phase solubility diagrams of all studied inclusion complexes at temperatures 30,37 , and $45^{\circ} \mathrm{C}$ are summarized in Figure 5 and Table S1, where the corresponding $K_{c}$ values are given in Table 2. The obtained results show that the increased $\beta C D(s)$ concentrations can enhance the solubility of MG in a liner manner (ranked in the order of $D M \beta C D>>2 H P \beta C D>\beta C D$ ), indicating that the stoichiometric ratio between $M G$ and $\beta C D(s)$ is 1:1 ( $A_{L}$ type) [41]. By considering the stability of all studied inclusion complexes at $30^{\circ} \mathrm{C}$, the highest $K_{c}$ value is detected in MG/DM $\beta C D\left(2245 \mathrm{M}^{-1}\right)$ followed by MG/HP $\beta C D\left(684 \mathrm{M}^{-1}\right)$ and MG/ $\beta C D\left(562 \mathrm{M}^{-1}\right)$, respectively. Moreover, the solubility of MG is dramatically increased up to $\sim 7$ times, $\sim 28$ times, and $\sim 10$ times by complexation with $\beta C D$, $\mathrm{DM} \beta C D$, and HP $\beta C D$, respectively (Table 4). These observations are consonant well with several reports demonstrating that $\beta C D$ derivatives, especially $D M \beta C D$, could significantly enhance the stability and solubility of hydrophobic guest molecules better than natural $\beta C D[25,53,54]$. However, the increased temperature remarkably reduces the stability of all investigated complexes, in a manner similar to previous works $[55,56]$.

Using Van't Hoff plot (see Supporting Information, Figure S1), the obtained thermodynamic values, i.e., $\Delta H, \Delta S$, and $\Delta G_{\text {bind, exp }}$, are summarized in Table 3. The negative $\Delta H(-20.77,-23.27$, and $-17.39 \mathrm{kcal} / \mathrm{mol}$ for $\mathrm{MG} / \beta \mathrm{CD}, \mathrm{MG} / \mathrm{DM} \beta \mathrm{CD}$, and $\mathrm{MG} / \mathrm{HP} \beta \mathrm{CD}$, respectively) suggests an exothermic process. Moreover, the formation of all inclusion complexes is spontaneous, as evidenced by the

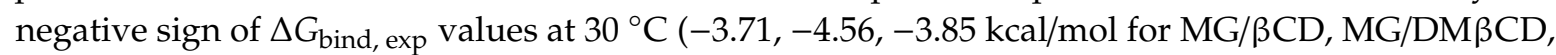
and MG/HP $\beta C D$, respectively). Notably, the trend of MM/GBSA-based free energies strongly agrees with $\Delta G_{\text {bind, exp }}$ values, indicating that MM/GBSA serves as a suitable method for predicting the binding affinity of $\mathrm{MG} / \beta \mathrm{CD}$ inclusion complexes, which is in good agreement with several studies on other host-guest systems [56-60].

Taken together, based on theoretical and experimental investigations, we selected the MG/DM $\beta C D$, showing the highest stability, for further structural characterizations in comparison to the $\mathrm{MG} / \beta C D$ and the free form of MG. 
- $\beta C D \quad \triangle D M \beta C D \quad H P \beta C D$

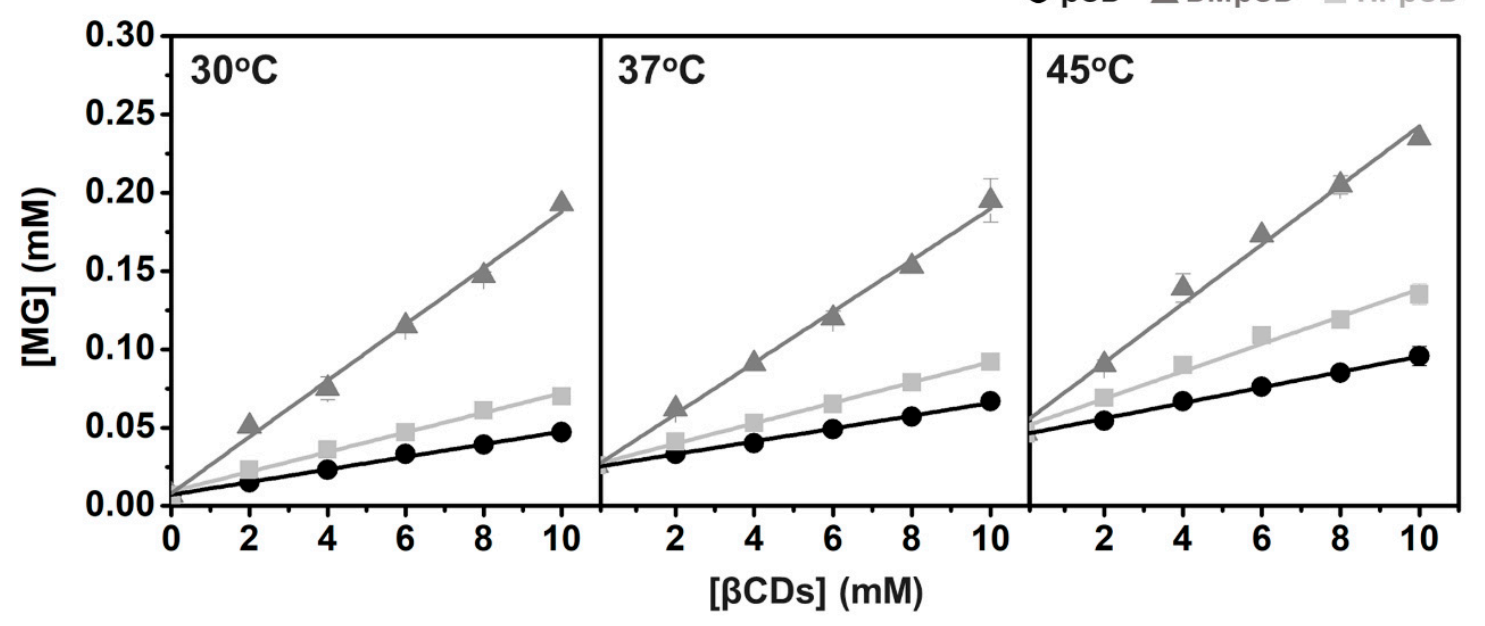

Figure 5. Phase solubility diagram of MG with all studied $\beta C D$ in water at $30^{\circ} \mathrm{C}, 37^{\circ} \mathrm{C}$, and $45^{\circ} \mathrm{C}$. An excess amount of $\mathrm{MG}$ was added to $\beta \mathrm{CD}(\mathrm{s})$ solutions $(0-10 \mathrm{mM})$. The mixtures were shaken (250 rpm) at $30{ }^{\circ} \mathrm{C}, 37^{\circ} \mathrm{C}$, and $45^{\circ} \mathrm{C}$ for $72 \mathrm{~h}$. Subsequently, the suspensions were centrifuged at $12,000 \mathrm{rpm}$ for $15 \mathrm{~min}$. The amount of MG presenting in solution was measured by UV-Vis spectroscopy at $415 \mathrm{~nm}$. Data are expressed as mean \pm SEM of three independent experiments.

Table 2. Kc of MG/ $\beta C D$ s inclusion complexes at different temperatures. Note that the $95 \%$ confidence interval and the other statistic values for the slope and the y-intercept of linear regression are shown in Table S2.

\begin{tabular}{cccc}
\hline \multirow{2}{*}{ Temperature $\left({ }^{\circ} \mathbf{C}\right)$} & \multicolumn{3}{c}{ Stability Constant $\left(\mathbf{K c}, \mathbf{M}^{-1}\right)$} \\
\cline { 2 - 4 } & $\mathbf{M G} / \boldsymbol{\beta C D}$ & $\mathbf{M G} / \mathbf{D M} \beta \mathbf{C D}$ & $\mathbf{M G} / \mathbf{H P} \beta \mathbf{C D}$ \\
\hline 30 & 562 & 2245 & 684 \\
37 & 165 & 643 & 245 \\
45 & 109 & 358 & 173 \\
\hline
\end{tabular}

Table 3. Thermodynamic values for the inclusion complex formation of MG with $\beta C D$ s derived from Van't Hoff plots (using R of $1.985 \times 10^{-3} \mathrm{kcal} \cdot \mathrm{mol}^{-1} \cdot \mathrm{K}^{-1}$ and $\mathrm{T}$ of $303 \mathrm{~K}$ ) in comparison to the $\Delta G_{\text {bind, MM/GBSA }}$. Note that the $95 \%$ confidence interval and the other statistic values for the slope and the y-intercept of linear regression are shown in Table S3.

\begin{tabular}{cccc}
\hline $\begin{array}{c}\text { Thermodynamic } \\
\text { Parameter (kcal/mol) }\end{array}$ & MG/ $\beta$ CD & MG/DM $\beta$ CD & MG/HP $\beta$ CD \\
\hline$\Delta H$ & -20.77 & -23.27 & -17.39 \\
$\mathrm{~T} \Delta S$ & -17.06 & -18.71 & -13.54 \\
$\Delta G_{\text {bind, exp }}\left(30^{\circ} \mathrm{C}\right)$ & -3.71 & -4.56 & -3.85 \\
\hline$\Delta G_{\text {bind, MM/GBSA }}$ & $-2.34 \pm 0.35$ & $-5.73 \pm 0.04$ & $-3.35 \pm 0.14$ \\
(Table 1) & & & \\
\hline
\end{tabular}

Table 4. Solubility of MG and its inclusion complexes at $30{ }^{\circ} \mathrm{C}$.

\begin{tabular}{cc}
\hline & Solubility of $\mathbf{M G ~} \mathbf{( m g / L )}$ \\
\hline MG & 1.7 \\
MG/ $\beta C D$ & 11.5 \\
MG/DM $\beta C D$ & 47.2 \\
MG/HP $\beta C D$ & 17.1 \\
\hline
\end{tabular}




\subsection{Inclusion Complex Characterization}

\subsubsection{Thermal Behavior of MG and Its Inclusion Complexes}

The thermal behaviors of the starting materials $(M G, \beta C D$, and $D M \beta C D)$ and the inclusion complexes (MG/ $\beta C D$ and MG/DM $\beta C D$ ) were characterized in the solid state by DSC analysis (Figure 6). The characteristic endothermic/exothermic peaks of the free compounds are as follows: $\mathrm{MG}$ at $208.7^{\circ} \mathrm{C}$ and $213.0^{\circ} \mathrm{C}, \beta C D$ at $118.9^{\circ} \mathrm{C}$, and $\mathrm{DM} \beta \mathrm{CD}$ at $77.1^{\circ} \mathrm{C}, 184.9^{\circ} \mathrm{C}$, and $293.9^{\circ} \mathrm{C}$. The broad endothermic peak of $\beta C D$ detected at $118.9^{\circ} \mathrm{C}$ corresponds to the release of water molecules from the hydrophobic cavity [61]. As shown in supplemental Figure S2, the distinct thermal peaks of the free MG were expressed in all the physical mixture products, indicating that the physical mixing method does not provide a real inclusion complex.

As a host-guest complexation process is occurred, the thermal features of the acquired product are dramatically changed [62]. In accordance with these facts, our data in Figure 6 reveal that the thermal peaks of the free MG were totally disappeared in all the freeze-dried inclusion complexes. In addition, in the case of $\mathrm{MG} / \beta C D$ inclusion complexation, the characteristic broad peak of $\beta C D$ at $118.9^{\circ} \mathrm{C}$ is shifted to $57.2^{\circ} \mathrm{C}$ by the influence of the MG-induced water replacement. The similar change of dehydration peak of $\beta C D$ after ligand complexation was also found by Rajendiran and coworkers [63]. Similarly, the broad endothermic peak $\left(77.1^{\circ} \mathrm{C}\right)$ and the exothermic peaks $\left(184.9^{\circ} \mathrm{C}\right.$ and $293.9^{\circ} \mathrm{C}$ ) of $\mathrm{DM} \beta \mathrm{CD}$ are dramatically shifted with a decreased intensity after complexing with MG, in good agreement with previous study [64]. Therefore, the freeze-drying method can successfully generate the new solid phase between MG and $\beta C D$ s.

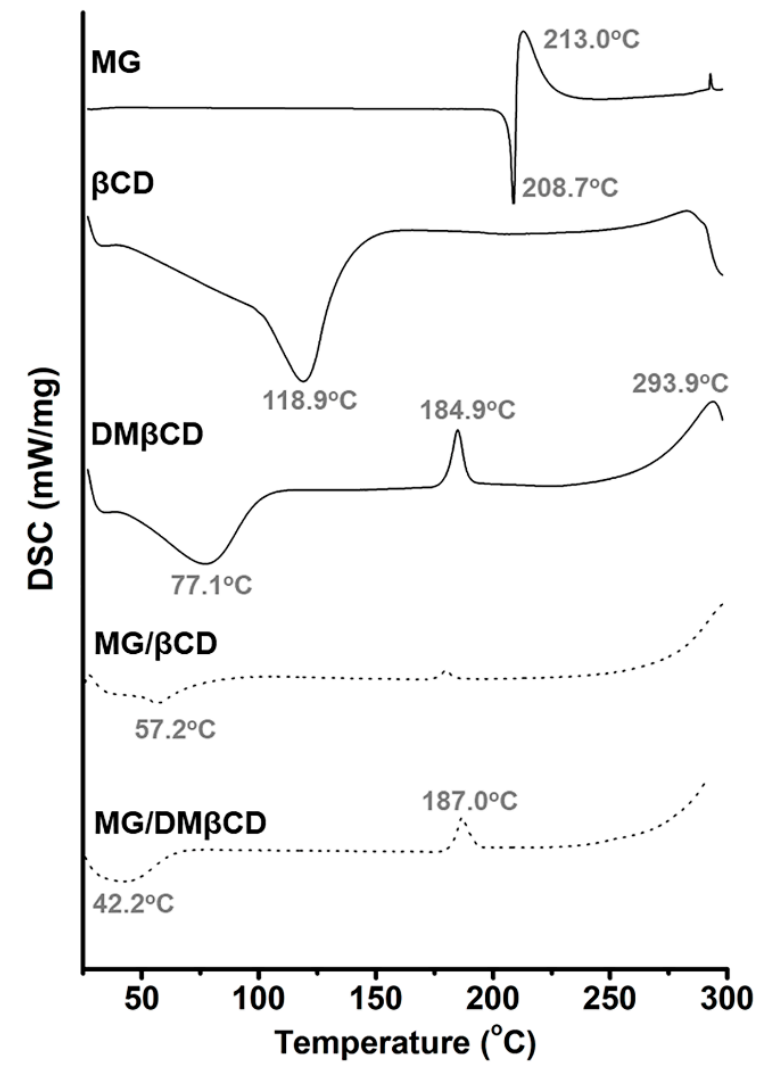

Figure 6. DSC thermogram of $M G, \beta C D, D M \beta C D$, and the freeze-dried inclusion complexes $(M G / \beta C D$ and $M G / D M \beta C D)$. Note that prior to perform DSC, all compounds were dissolved in deionized water and were subsequently lyophilized for 3 days. 


\subsubsection{Surface Morphological Changes upon Inclusion Complexation}

It was evident that the inclusion complex formation dramatically induces the alterations of the particle shape and surface morphology of the resulting products [65-67]; thus, we performed SEM analysis in order to characterize the morphological changes upon host-guest encapsulation. The SEM micrographs at 300 times magnification of all investigated samples are summarized in Figure 7. In the case of the unbound forms, $\beta C D$ and $D M \beta C D$ are defined as rod-shaped structure, in accord with previous reports $[68,69]$, whereas MG displays a flake-like feature. Upon molecular complexation, the surface morphology and the particle shape/size of the obtained freeze-dried inclusion complexes $\mathrm{MG} / \beta \mathrm{CD}$ and $\mathrm{MG} / \mathrm{DM} \beta \mathrm{CD}$ (Figure $7 \mathrm{D}, \mathrm{E}$ ) are totally different from those of the free forms, confirming the successful formation between MG and $\beta C D$ s.
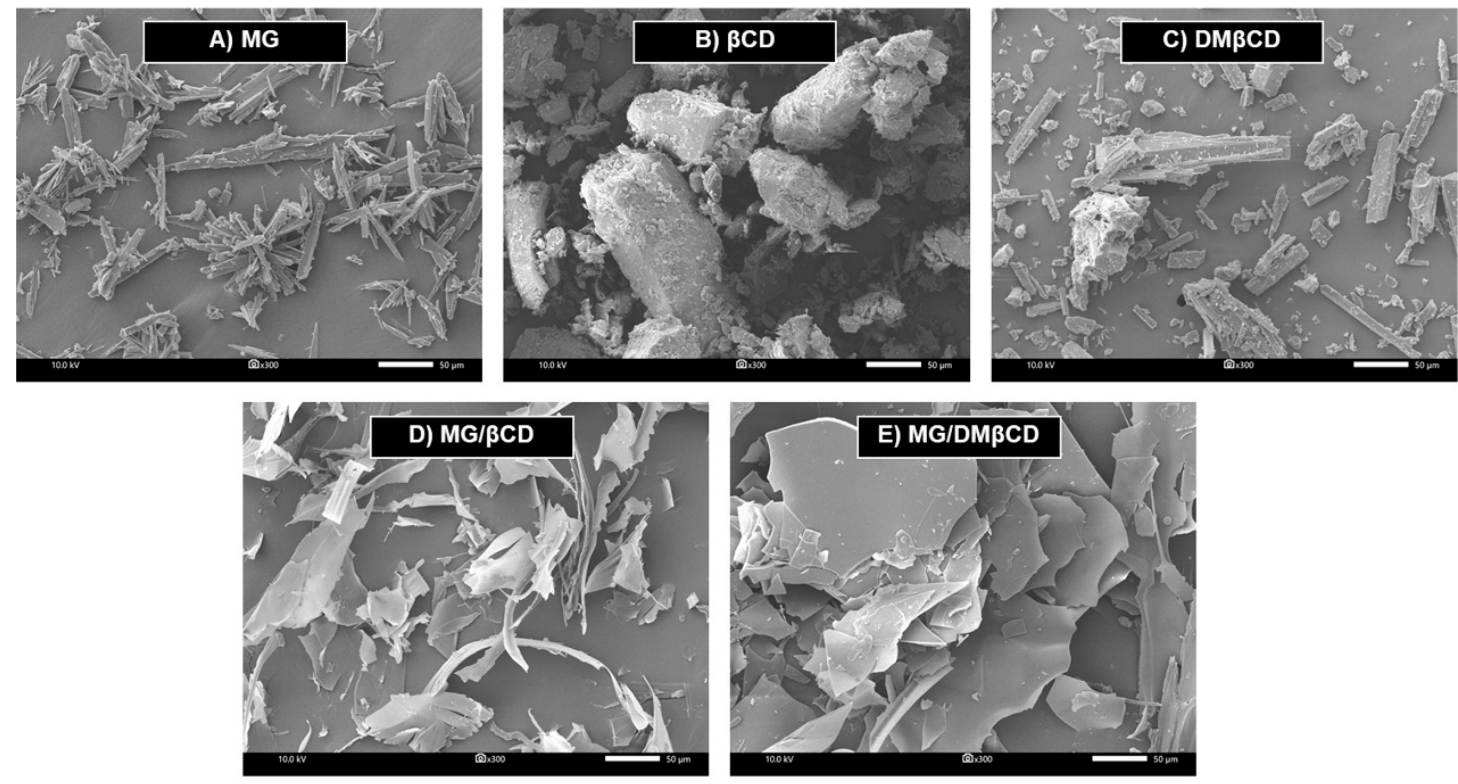

Figure 7. SEM images of (A) MG, (B) $\beta C D$, (C) $D M \beta C D$, (D) $M G / \beta C D$, and (E) $M G / D M \beta C D$ at 300 times magnification.

\subsection{Cytotoxicity of MG/ $\beta C D$ s Inclusion Complexes toward Lung Cancer}

Lung cancer is the first leading cause of cancer-related death globally with its five-year survival rate of only $17.8 \%$ [70]. In this study, we evaluated the cytotoxic activity of MG and its inclusion complexes (MG/ $\beta C D, M G / D M \beta C D$, and $M G / H P \beta C D)$ against $A 549$ human lung cancer cell line using MTT assay. The cell viability (\% of control) results are summarized in Figure $8 \mathrm{~A}$, whereas the $\mathrm{IC}_{50}$ values $(\mu \mathrm{M})$ are shown in Figure $8 \mathrm{~B}$. The obtained results reveal that MG, MG/ $\beta C D, M G / D M \beta C D$, and MG/HP $\beta C D$ decrease cell viability in a concentration-dependent manner, in which MG/HP $\beta C D$ exhibits the lowest cell viability followed by $M G / D M \beta C D, M G / \beta C D$, and $M G$, respectively (Figure $8 \mathrm{~A}$ ).

Multiple lines of evidence have shown that $\beta C D$ inclusion complexations can potentially enhance the antitumor activity of lipophilic guest compounds $[25,67,71]$. In correlation with these reports, the present study shows that the inclusion complexes of MG significantly increase the anticancer effect on A549 cells, which can be ranked in the order of MG/HP $\beta C D\left(\mathrm{IC}_{50}\right.$ of $\left.5.62 \pm 0.40 \mu \mathrm{M},{ }^{* * *}\right)>$ $\mathrm{MG} / \mathrm{DM} \beta \mathrm{CD}\left(\mathrm{IC}_{50}\right.$ of $\left.13.45 \pm 0.24 \mu \mathrm{M},{ }^{* * *}\right)>\mathrm{MG} / \beta \mathrm{CD}\left(17.63 \pm 0.42 \mu \mathrm{M},{ }^{* * *}\right)>>\mathrm{MG}(42.86 \pm 2.09 \mu \mathrm{M})$ (Figure $8 \mathrm{~B}$ ). The enhancement of anticancer activity of MG by complexation with $\beta C D$ s is likely due to the reason that $\beta C D$ s can infiltrate into the drug permeation barrier, called unstirred water layer (UWL) consisting of a large number of strong H-bond networks [72], better than the free form of lipophilic MG. It is likely that the introduced hydrophilic HP (HP $\beta C D)$ and the hydrophobic methyl groups on $\beta C D(D M \beta C D)$ could respectively (i) enhance the flux of drug though UWL [73] and (ii) interact with biological membrane greater than unmodified CD [74]. Therefore, the cytotoxic effect on A549 
of $M G / H P \beta C D$ and $M G / D M \beta C D$ is higher than that of $M G / \beta C D$. Importantly, the free form of $\beta C D$, $D M \beta C D$, and $H P \beta C D$ does not affect the antitumor property of $M G / \beta C D$ s inclusion complexes, as evidenced by the cell viability values of $>90 \%$ (Figure $8 \mathrm{C}$ ).
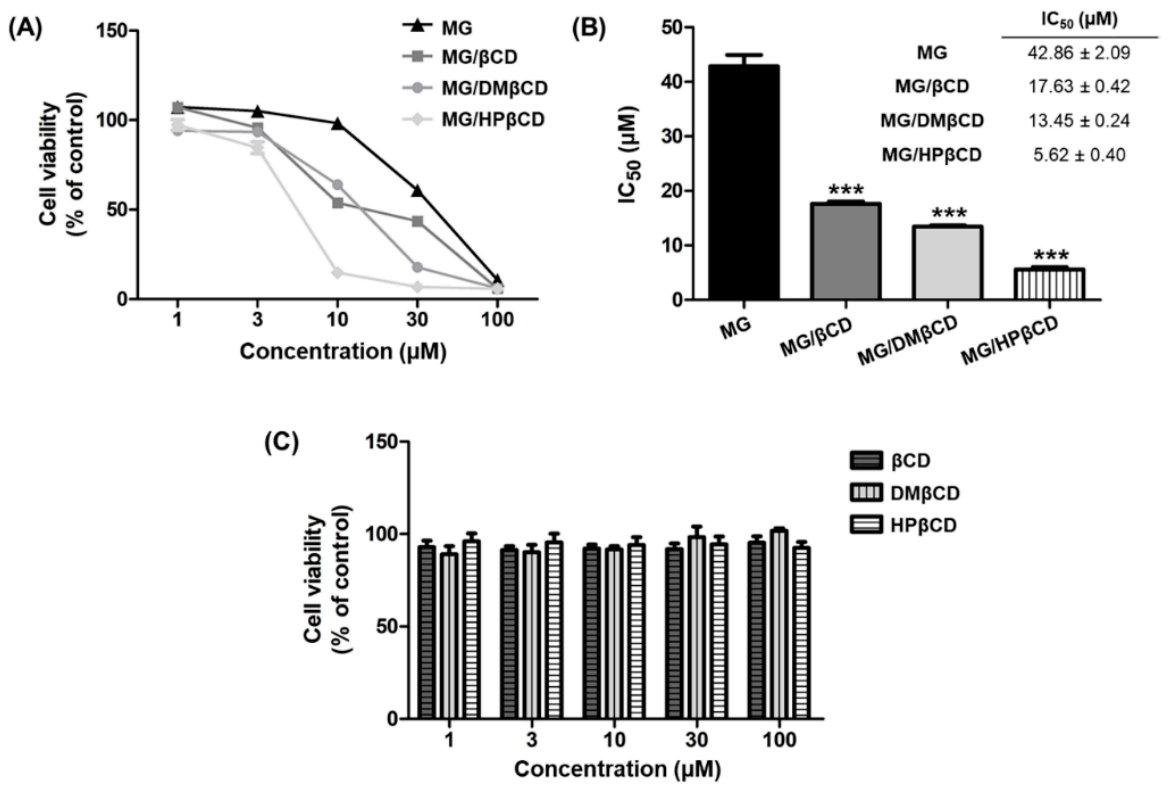

Figure 8. (A) Cell viability of A549 human lung cell line after treatment with logarithmic concentrations $(1,3,10,30$, and $100 \mu \mathrm{M})$ of MG, MG/ $\beta C D, M G / D M \beta C D$, and MG/HP $\beta C D$ for $48 \mathrm{~h}$. (B) The $\mathrm{IC}_{50}$ $(\mu \mathrm{M})$ of all investigated compounds. (C) Cell viability of A549 cells treated with the free form of $\beta C D, D M \beta C D$, and HP $\beta C D$. Data are expressed as mean \pm SEM of three independent experiments. *** $p \leq 0.001$ vs. MG.

\section{Conclusions}

In the present study, we combined theoretical and experimental studies to identify the most suitable $\beta C D$ host molecule for MG, a promising anticancer agent extracted from Mansonia gagei, for improving the aqueous solubility and the antitumor potential. The 90-ns MD simulations in triplicate revealed that MG preferentially positioned inside $\beta C D, D M \beta C D$, and $2 \mathrm{HP} \beta C D$ cavities through its aromatic ring. The MG binding led to the rigidity of $\beta C D$ s by increasing the intramolecular $\mathrm{H}$-bond formations on the wider rim. Among the three different MG/ $\beta C D$ s, the $\Delta G_{\text {bind }}$ values from MM/GBSA calculations and experimental phase solubility study revealed that $\mathrm{MG} / \mathrm{DM} \beta \mathrm{CD}$ was the most stable complex, as supported by the lowest water accessibility toward MG atomic radii and the highest number of contacts between host and guest molecules. The successful formation of MG/ $\beta C D$ s was confirmed by DSC and SEM techniques. The anticancer activity of MG toward A549 lung cancer cells was significantly enhanced ( 2-7 fold) by complexation with $\beta C D$ s, especially HP $\beta C D$ and DM $\beta C D$ analogs. Altogether, the obtained results confirmed the working hypothesis and demonstrated the good potentiality of $\beta C D$ derivatives as suitable formulations of MG for further pharmaceutical and medicinal applications.

Supplementary Materials: The following are available online at http://www.mdpi.com/2218-273X/9/10/545/s1, Figure S1: Van't Hoff plots of MG/ $\beta C D$ s inclusion complexes., Figure S2: DSC thermogram of MG, $\beta C D, D M \beta C D$, and the physical mixtures $\mathrm{MG} / \beta \mathrm{CD}$ and $\mathrm{MG} / \mathrm{DM} \beta \mathrm{CD}$. Note that prior to perform DSC, all compounds were not dissolved in deionized water and were not subsequently lyophilized., Table S1: Linear equation of MG/ $\beta C D$ s inclusion complexes at different temperatures derived from Figure 5., Table S2: The 95\% confidence interval and the other statistic values for the slope and the y-intercept of linear regression of phase solubility study derived from Figure 5., Table S3: The 95\% confidence interval and the other statistic values for the slope and the y-intercept of linear regression of Van't Hoff plot derived from Figure S1. 
Author Contributions: P.M. and T.R.; conceptualization. P.M. conducted theoretical and experimental studies. T.C. and P.W.; methodology. M.P. and P.W.; resources. W.C. purified, synthesized, and identified MG using NMR. P.M., T.R., P.W., and T.C. analyzed the data. P.M. wrote the original manuscript. All authors reviewed and edited the manuscript. T.R.; funding acquisition.

Funding: This research was funded by the Thailand Research Fund (grant number RSA6280085). P.M. thanks the Science Achievement Scholarship of Thailand for Ph.D. scholarship, the 90th Anniversary of Chulalongkorn University Fund (Ratchadaphiseksomphot Endowment Fund), and the Overseas Presentations of Graduate Level Academic Thesis from Graduate School. The Chulalongkorn Academic Advancement into its 2nd Century Project (Project [CUAASC] and Chulalongkorn University's Ratchadapisek Sompot Fund [grant number GCURP59022301]) are acknowledged for computing resources.

Conflicts of Interest: The authors declare no conflict of interest.

\section{References}

1. Nagai, H.; Kim, Y.H. Cancer prevention from the perspective of global cancer burden patterns. J. Thorac. Dis. 2017, 9, 448-451. [CrossRef] [PubMed]

2. Pardee, A.B.; Li, Y.Z.; Li, C.J. Cancer therapy with beta-lapachone. Curr. Cancer Drug Targets 2002, 2, $227-242$. [CrossRef] [PubMed]

3. Aziz, M.H.; Dreckschmidt, N.E.; Verma, A.K. Plumbagin, a medicinal plant-derived naphthoquinone, is a novel inhibitor of the growth and invasion of hormone-refractory prostate cancer. Cancer Res. 2008, 68, 9024-9032. [CrossRef] [PubMed]

4. Hou, Y.; Xu, J.; Liu, X.; Xia, X.; Li, N.; Bi, X. Shikonin induces apoptosis in the human gastric cancer cells HGC-27 through mitochondria-mediated pathway. Pharmacogn. Mag. 2015, 11, 250-256. [CrossRef] [PubMed]

5. Baghdadi, M.A.; Al-Abbasi, F.A.; El-Halawany, A.M.; Aseeri, A.H.; Al-Abd, A.M. Anticancer Profiling for Coumarins and Related O-Naphthoquinones from Mansonia gagei against Solid Tumor Cells In Vitro. Molecules 2018, 23, 1020. [CrossRef] [PubMed]

6. Wang, D.; Xia, M.; Cui, Z.; Tashiro, S.-I.; Onodera, S.; Ikejima, T. Cytotoxic effects of mansonone E and F isolated from Ulmus pumila. Boil. Pharm. Bull. 2004, 27, 1025-1030. [CrossRef]

7. Liu, Z.; Huang, S.-L.; Li, M.-M.; Huang, Z.-S.; Lee, K.S.; Gu, L.-Q. Inhibition of thioredoxin reductase by mansonone F analogues: Implications for anticancer activity. Chem. Interactions 2009, 177, 48-57. [CrossRef]

8. Johnson, J.; Gandhidasan, I.; Murugesan, R. Cytotoxicity and superoxide anion generation by some naturally occurring quinones. Free. Radic. Boil. Med. 1999, 26, 1072-1078. [CrossRef]

9. Wu, W.-B.; Ou, J.-B.; Huang, Z.-H.; Chen, S.-B.; Ou, T.-M.; Tan, J.-H.; Li, D.; Shen, L.-L.; Huang, S.-L.; Gu, L.-Q.; et al. Synthesis and evaluation of mansonone F derivatives as topoisomerase inhibitors. Eur. J. Med. Chem. 2011, 46, 3339-3347. [CrossRef]

10. Tanaka, N.; Yasue, M.; Imamura, H. The quinonoid pigments of mansonia altissima wood. Tetrahedron Lett. 1966, 7, 2767-2773. [CrossRef]

11. Hairani, R.; Mongkol, R.; Chavasiri, W. Allyl and prenyl ethers of mansonone G, new potential semisynthetic antibacterial agents. Bioorganic Med. Chem. Lett. 2016, 26, 5300-5303. [CrossRef] [PubMed]

12. Aljohani, H.G.; Hegazy, G.A.; AlAmoudi, A.A.; Agabnoor, G.M.; El-Halawany, A.M.; Al-Abd, A.M. Abstract LB-073: Mansonone-G is more potent antiproliferative against liver cancer cells than its coumarin derivative (mansorin-A) despite their antagonistic interaction with 5-fluorouracil. Cancer Chem. 2018, 78. [CrossRef]

13. Dai, Y.; Harinantenaina, L.; Brodie, P.J.; Callmander, M.W.; Randrianasolo, S.; Rakotobe, E.; Rasamison, V.E.; Kingston, D.G.I. Isolation and synthesis of two antiproliferative calamenene-type sesquiterpenoids from Sterculia tavia from the Madagascar rain forest. Bioorganic Med. Chem. 2012, 20, 6940-6944. [CrossRef] [PubMed]

14. Mahalapbutr, P.; Wonganan, P.; Chavasiri, W.; Rungrotmongkol, T. Butoxy Mansonone G Inhibits STAT3 and Akt Signaling Pathways in Non-Small Cell Lung Cancers: Combined Experimental and Theoretical Investigations. Cancers 2019, 11, 437. [CrossRef] [PubMed]

15. Szejtli, J. Introduction and General Overview of Cyclodextrin Chemistry. Chem. Rev. 1998, 98, 1743-1754. [CrossRef] [PubMed] 
16. De Carvalho, L.B.; Burusco, K.K.; Jaime, C.; Venâncio, T.; De Carvalho, A.F.S.; Murgas, L.D.S.; Pinto, L.D.M.A.; Burusco-Goni, K.K. Complexes between methyltestosterone and $\beta$-cyclodextrin for application in aquaculture production. Carbohydr. Polym. 2018, 179, 386-393. [CrossRef] [PubMed]

17. Tommasini, S.; Raneri, D.; Ficarra, R.; Calabrò, M.L.; Stancanelli, R.; Ficarra, P. Improvement in solubility and dissolution rate of flavonoids by complexation with $\beta$-cyclodextrin. J. Pharm. Biomed. Anal. 2004, 35, 379-387. [CrossRef]

18. Veiga, M.D.; Díaz, P.J.; Ahsan, F. Interactions of Griseofulvin with Cyclodextrins in Solid Binary Systems. J. Pharm. Sci. 1998, 87, 891-900. [CrossRef]

19. Del Valle, E.M.M. Cyclodextrins and their uses: A review. Process Biochem. 2004, 39, 1033-1046. [CrossRef]

20. Vaidya, B.; Shukla, S.K.; Kolluru, S.; Huen, M.; Mulla, N.; Mehra, N.; Kanabar, D.; Palakurthi, S.; Ayehunie, S.; Muth, A.; et al. Nintedanib-cyclodextrin complex to improve bio-activity and intestinal permeability. Carbohydr. Polym. 2019, 204, 68-77. [CrossRef]

21. Zhao, Y.; Sun, C.; Shi, F.; Firempong, C.K.; Yu, J.; Xu, X.; Zhang, W. Preparation, characterization, and pharmacokinetics study of capsaicin via hydroxypropyl-beta-cyclodextrin encapsulation. Pharm. Biol. 2016, 54, 130-138. [CrossRef] [PubMed]

22. Loftsson, T.; Másson, M. Cyclodextrins in topical drug formulations: theory and practice. Int. J. Pharm. 2001, 225, 15-30. [CrossRef]

23. de Araujo, D.R.; Tsuneda, S.S.; Cereda, C.M.S.; Del, G.F.; Carvalho, F.; Preté, P.S.C.; Fernandes, S.A.; Yokaichiya, F.; Franco, M.K.K.D.; Mazzaro, I.; et al. Development and pharmacological evaluation of ropivacaine-2-hydroxypropyl-beta-cyclodextrin inclusion complex. Eur. J. Pharm. Sci. 2008, 33, 60-71. [CrossRef] [PubMed]

24. Kai-Hang, L.; Mengying, S.; Guping, T.; Xiurong, H.U. [Preparation, characterization and antitumor of cyclodextrin inclusion of an anti-cancer drug regorafenib]. Zhejiang da xue xue bao. Yi xue ban = Journal of Zhejiang University. Med Sci. 2017, 46, 151-159.

25. Kikuchi, M.; Uekama, K. Effect of Dimethyl \&beta;-Cyclodextrin on Oral or Rectal Absorption of 1-Hexylcarbamoyl-5-fluorouracil (HCFU). Yakugaku Zasshi 1988, 108, 156-163. [CrossRef] [PubMed]

26. Kicuntod, J.; Sangpheak, K.; Mueller, M.; Wolschann, P.; Viernstein, H.; Yanaka, S.; Kato, K.; Chavasiri, W.; Pongsawasdi, P.; Kungwan, N.; et al. Theoretical and Experimental Studies on Inclusion Complexes of Pinostrobin and beta-Cyclodextrins. Sci. Pharm. 2018, 86, 5. [CrossRef] [PubMed]

27. Ramos, A.I.; Vaz, P.D.; Braga, S.S.; Silva, A.M.S. Association of aescin with $\beta$ - and $\gamma$-cyclodextrins studied by DFT calculations and spectroscopic methods. Beilstein J. Nanotechnol. 2017, 8, 348-357. [CrossRef] [PubMed]

28. Aree, T.; Jongrungruangchok, S. Structure-antioxidant activity relationship of beta-cyclodextrin inclusion complexes with olive tyrosol, hydroxytyrosol and oleuropein: Deep insights from X-ray analysis, DFT calculation and DPPH assay. Carbohydr. Polym. 2018, 199, 661-669. [CrossRef] [PubMed]

29. Mahalapbutr, P.; Chusuth, P.; Kungwan, N.; Chavasiri, W.; Wolschann, P.; Rungrotmongkol, T. Molecular recognition of naphthoquinone-containing compounds against human DNA topoisomerase II $\alpha$ ATPase domain: A molecular modeling study. J. Mol. Liq. 2017, 247, 374-385. [CrossRef]

30. Kicuntod, J.; Khuntawee, W.; Wolschann, P.; Pongsawasdi, P.; Chavasiri, W.; Kungwan, N.; Rungrotmongkol, T. Inclusion complexation of pinostrobin with various cyclodextrin derivatives. J. Mol. Graph. Model. 2016, 63, 91-98. [CrossRef] [PubMed]

31. Sangpheak, W.; Khuntawee, W.; Wolschann, P.; Pongsawasdi, P.; Rungrotmongkol, T. Enhanced stability of a naringenin/2,6-dimethyl beta-cyclodextrin inclusion complex: Molecular dynamics and free energy calculations based on MM- and QM-PBSA/GBSA. J. Mol. Graph. Model. 2014, 50, 10-15. [CrossRef] [PubMed]

32. Kim, H.K.; Hairani, R.; Jeong, H.; Jeong, M.G.; Chavasiri, W.; Hwang, E.S. CBMG, a novel derivative of mansonone $\mathrm{G}$ suppresses adipocyte differentiation via suppression of PPARgamma activity. Chemico-Biol. Interact. 2017, 273, 160-170. [CrossRef] [PubMed]

33. Hanpaibool, C.; Chakcharoensap, T.; Arifin; Hijikata, Y.; Irle, S.; Wolschann, P.; Kungwan, N.; Pongsawasdi, P.; Ounjai, P.; Rungrotmongkol, T. Theoretical analysis of orientations and tautomerization of genistein in $\beta$-cyclodextrin. J. Mol. Liq. 2018, 265, 16-23. [CrossRef]

34. Mahalapbutr, P.; Thitinanthavet, K.; Kedkham, T.; Nguyen, H.; Theu, L.T.H.; Dokmaisrijan, S.; Huynh, L.; Kungwan, N.; Rungrotmongkol, T. A theoretical study on the molecular encapsulation of luteolin and pinocembrin with various derivatized beta-cyclodextrins. J. Mol. Struct. 2019, 1180, 480-490. [CrossRef] 
35. Mahalapbutr, P.; Darai, N.; Panman, W.; Opasmahakul, A.; Kungwan, N.; Hannongbua, S.; Rungrotmongkol, T. Atomistic mechanisms underlying the activation of the $\mathrm{G}$ protein-coupled sweet receptor heterodimer by sugar alcohol recognition. Sci. Rep. 2019, 9, 10205. [CrossRef]

36. Kirschner, K.N.; Yongye, A.B.; Tschampel, S.M.; Gonzalez-Outeirino, J.; Daniels, C.R.; Foley, B.L.; Woods, R.J. GLYCAM06: A generalizable biomolecular force field. Carbohydrates. J. Comput. Chem. 2008, 29, 622-655. [CrossRef]

37. Wang, J.; Wolf, R.M.; Caldwell, J.W.; Kollman, P.A.; Case, D.A. Development and testing of a general amber force field. J. Comput. Chem. 2004, 25, 1157-1174. [CrossRef] [PubMed]

38. Ryckaert, J.-P.; Ciccotti, G.; Berendsen, H.J. Numerical integration of the cartesian equations of motion of a system with constraints: molecular dynamics of n-alkanes. J. Comput. Phys. 1977, 23, 327-341. [CrossRef]

39. Luty, B.A.; Van Gunsteren, W.F. Calculating Electrostatic Interactions Using the Particle-Particle Particle-Mesh Method with Nonperiodic Long-Range Interactions. J. Phys. Chem. 1996, 100, 2581-2587. [CrossRef]

40. Genheden, S.; Ryde, U. The MM/PBSA and MM/GBSA methods to estimate ligand-binding affinities. Expert Opin. Drug Discov. 2015, 10, 449-461. [CrossRef]

41. Higuchi, T. A phase solubility technique. Adv. Anal. Chem. Instrum. 1965, 4, 117-211.

42. Mahalapbutr, P.; Nutho, B.; Wolschann, P.; Chavasiri, W.; Kungwan, N.; Rungrotmongkol, T. Molecular insights into inclusion complexes of mansonone $\mathrm{E}$ and $\mathrm{H}$ enantiomers with various beta-cyclodextrins. J. Mol. Graph. Model. 2018, 79, 72-80. [CrossRef] [PubMed]

43. Yang, L.J.; Ma, S.X.; Zhou, S.Y.; Chen, W.; Yuan, M.W.; Yin, Y.Q.; Yang, X.D. Preparation and characterization of inclusion complexes of naringenin with beta-cyclodextrin or its derivative. Carbohydr. Polym. 2013, 98, 861-869. [CrossRef] [PubMed]

44. Wongpituk, P.; Nutho, B.; Panman, W.; Kungwan, N.; Wolschann, P.; Rungrotmongkol, T.; Nunthaboot, N. Structural dynamics and binding free energy of neral-cyclodextrins inclusion complexes: molecular dynamics simulation. Mol. Simul. 2017, 43, 1356-1363. [CrossRef]

45. Ren, B.; Gao, H.; Cao, Y.; Jia, L. In Silico understanding of the cyclodextrin-phenanthrene hybrid assemblies in both aqueous medium and bacterial membranes. J. Hazard. Mater. 2015, 285, 148-156. [CrossRef] [PubMed]

46. Mongan, J.; Simmerling, C.; McCammon, J.A.; Case, D.A.; Onufriev, A. Generalized Born model with a simple, robust molecular volume correction. J. Chem. Theory Comput. 2007, 3, 156-169. [CrossRef] [PubMed]

47. Chen, W.; Chang, C.-E.; Gilson, M.K. Calculation of Cyclodextrin Binding Affinities: Energy, Entropy, and Implications for Drug Design. Biophys. J. 2004, 87, 3035-3049. [CrossRef] [PubMed]

48. Fermeglia, M.; Ferrone, M.; Lodi, A.; Pricl, S. Host-guest inclusion complexes between anticancer drugs and $\beta$-cyclodextrin: computational studies. Carbohydr. Polym. 2003, 53, 15-44. [CrossRef]

49. Liu, L.; Guo, Q.-X. The Driving Forces in the Inclusion Complexation of Cyclodextrins. J. Incl. Phenom. Macrocycl. Chem. 2002, 42,1-14. [CrossRef]

50. Jullian, C.; Cifuentes, C.; Alfaro, M.; Miranda, S.; Barriga, G.; Olea-Azar, C. Spectroscopic characterization of the inclusion complexes of luteolin with native and derivatized $\beta$-cyclodextrin. Bioorganic Med. Chem. 2010, 18, 5025-5031. [CrossRef]

51. Wang, D.W.; Ouyang, C.B.; Liu, Q.; Yuan, H.L.; Liu, X.H. Inclusion of quinestrol and 2,6-di-O-methyl-beta-cyclodextrin: Preparation, characterization, and inclusion mode. Carbohydr. Polym. 2013, 93, 753-760. [CrossRef] [PubMed]

52. Jullian, C.; Morales-Montecinos, J.; Zapata-Torres, G.; Aguilera, B.; Rodriguez, J.; Arán, V.; Olea-Azar, C.; Aguilera-Venegas, B.; Rodríguez-Becerra, J. Characterization, phase-solubility, and molecular modeling of inclusion complex of 5-nitroindazole derivative with cyclodextrins. Bioorganic Med. Chem. 2008, 16, 5078-5084. [CrossRef] [PubMed]

53. Tang, P.; Wang, L.; Ma, X.; Xu, K.; Xiong, X.; Liao, X.; Li, H. Characterization and In Vitro Evaluation of the Complexes of Posaconazole with $\beta$ - and 2,6-di-O-methyl- $\beta$-cyclodextrin. AAPS PharmSciTech 2017, 18, 104-114. [CrossRef] [PubMed]

54. Wang, L.; Li, S.; Tang, P.; Yan, J.; Xu, K.; Li, H. Characterization and evaluation of synthetic riluzole with $\beta$-cyclodextrin and 2,6-di-O-methyl- $\beta$-cyclodextrin inclusion complexes. Carbohydr. Polym. 2015, 129, 9-16. [CrossRef] [PubMed]

55. I Saleh, S.; A Rahman, A.; E Aboutaleb, A.; Nakai, Y.; O Ahmed, M. Effect of dimethyl-beta-cyclodextrin on nitrazepam stability. J. de Pharm. de Belg. 1993, 48, 383-388. 
56. Sangpheak, W.; Kicuntod, J.; Schuster, R.; Rungrotmongkol, T.; Wolschann, P.; Kungwan, N.; Viernstein, H.; Mueller, M.; Pongsawasdi, P. Physical properties and biological activities of hesperetin and naringenin in complex with methylated beta-cyclodextrin. Beilstein J. Org. Chem. 2015, 11, 2763-2773. [CrossRef]

57. Rungrotmongkol, T.; Chakcharoensap, T.; Pongsawasdi, P.; Kungwan, N.; Wolschann, P. The inclusion complexation of daidzein with $\beta$-cyclodextrin and 2,6-dimethyl- $\beta$-cyclodextrin: a theoretical and experimental study. Mon. für Chem. - Chem. Mon. 2018, 149, 1739-1747. [CrossRef]

58. Suarez, D.; Diaz, N. Affinity Calculations of Cyclodextrin Host-Guest Complexes: Assessment of Strengths and Weaknesses of End-Point Free Energy Methods. J. Chem. Inf. Modeling 2019, 59, 421-440. [CrossRef]

59. Genheden, S. MM/GBSA and LIE estimates of host-guest affinities: Dependence on charges and solvation model. J. Comput. Mol. Des. 2011, 25, 1085-1093. [CrossRef]

60. Suwandecha, T.; Rungnim, C.; Namuangruk, S.; Ruktanonchai, U.; Sawatdee, S.; Dechraksa, J.; Srichana, T. Host-guest interactions between sildenafil and cyclodextrins: Spectrofluorometric study and molecular dynamic modeling. J. Mol. Graph. Model. 2017, 77, 115-120. [CrossRef]

61. Hădărugă, N.G.; Hădărugă, D.I.; Paunescu, V.; Tatu, C.; Ordodi, V.L.; Bandur, G.; Lupea, A.X. Thermal stability of the linoleic acid/ $\alpha$ - and $\beta$-cyclodextrin complexes. Food Chem. 2006, 99, 500-508. [CrossRef]

62. Abarca, R.L.; Rodriguez, F.J.; Guarda, A.; Galotto, M.J.; Bruna, J.E. Characterization of beta-cyclodextrin inclusion complexes containing an essential oil component. Food Chem. 2016, 196, 968-975. [CrossRef] [PubMed]

63. Rajendiran, N.; Siva, S. Inclusion complex of sulfadimethoxine with cyclodextrins: Preparation and characterization. Carbohydr. Polym. 2014, 101, 828-836. [CrossRef] [PubMed]

64. Ventura, C.A.; Giannone, I.; Paolino, D.; Pistara, V.; Corsaro, A.; Puglisi, G. Preparation of celecoxib-dimethyl-beta-cyclodextrin inclusion complex: Characterization and in vitro permeation study. Eur. J. Med. Chem. 2005, 40, 624-631. [CrossRef] [PubMed]

65. Rakmai, J.; Cheirsilp, B.; Mejuto, J.C.; Simal-Gándara, J.; Torrado-Agrasar, A. Antioxidant and antimicrobial properties of encapsulated guava leaf oil in hydroxypropyl-beta-cyclodextrin. Ind. Crops Prod. 2018, 111, 219-225. [CrossRef]

66. Zarif, M.S.; Afidah, A.R.; Abdullah, J.M.; Shariza, A.R. Physicochemical characterization of vancomycin and its complexes with $\beta$-cyclodextrin. Biomed. Res. (In India) 2012, 23, 513-520.

67. Yallapu, M.M.; Jaggi, M.; Chauhan, S.C. $\beta$-Cyclodextrin-curcumin self-assembly enhances curcumin delivery in prostate cancer cells. Colloids Surf. B: Biointerfaces 2010, 79, 113-125. [CrossRef]

68. Rajbanshi, B.; Saha, S.; Das, K.; Barman, B.K.; Sengupta, S.; Bhattacharjee, A.; Roy, M.N. Study to Probe Subsistence of Host-Guest Inclusion Complexes of $\alpha$ and $\beta$-Cyclodextrins with Biologically Potent Drugs for Safety Regulatory Dischargement. Sci. Rep. 2018, 8, 13031. [CrossRef]

69. Gil Choi, S.; Lee, S.-E.; Kang, B.-S.; Ng, C.L.; Davaa, E.; Park, J.-S. Thermosensitive and Mucoadhesive Sol-Gel Composites of Paclitaxel/Dimethyl- $\beta$-Cyclodextrin for Buccal Delivery. PLOS ONE 2014, 9, e109090.

70. Wong, M.C.S.; Lao, X.Q.; Ho, K.-F.; Goggins, W.B.; Tse, S.L.A. Incidence and mortality of lung cancer: global trends and association with socioeconomic status. Sci. Rep. 2017, 7, 14300. [CrossRef]

71. Wang, F.; Yang, B.; Zhao, Y.; Liao, X.; Gao, C.; Jiang, R.; Han, B.; Yang, J.; Liu, M.; Zhou, R. Host-guest inclusion system of scutellarein with 2-hydroxypropyl-beta-cyclodextrin: preparation, characterization, and anticancer activity. J. Biomater. Sci. Polym. Ed. 2014, 25, 594-607. [CrossRef] [PubMed]

72. Loftsson, T. Drug permeation through biomembranes: cyclodextrins and the unstirred water layer. Die Pharm. 2012, 67, 363-370.

73. Brewster, M.E.; Noppe, M.; Peeters, J.; Loftsson, T. Effect of the unstirred water layer on permeability enhancement by hydrophilic cyclodextrins. Int. J. Pharm. 2007, 342, 250-253. [CrossRef] [PubMed]

74. Nishijo, J.; Shiota, S.; Mazima, K.; Inoue, Y.; Mizuno, H.; Yoshida, J. Interactions of Cyclodextrins with Dipalmitoyl, Distearoyl, and Dimyristoyl Phosphatidyl Choline Liposomes. A Study by Leakage of Carboxyfluorescein in Inner Aqueous Phase of Unilamellar Liposomes. Chem. Pharm. Bull. 2000, 48, 48-52. [CrossRef] [PubMed]

(C) 2019 by the authors. Licensee MDPI, Basel, Switzerland. This article is an open access article distributed under the terms and conditions of the Creative Commons Attribution (CC BY) license (http://creativecommons.org/licenses/by/4.0/). 